\title{
HT-2 and T-2 toxins in Norwegian oat grains related to weather conditions at different growth stages
}

\author{
Anne-Grete Roer Hjelkrem • Heidi Udnes Aamot • Guro Brodal • Einar C. Strand • \\ Torfinn Torp • Simon G. Edwards • Ruth Dill-Macky • Ingerd Skow Hofgaard
}

Accepted: 6 December 2017 / Published online: 8 January 2018

(C) The Author(s) 2018. This article is an open access publication
Electronic supplementary material The online version of this article (https://doi.org/10.1007/s10658-017-1394-3) contains supplementary material, which is available to authorized users.

A.-G. R. Hjelkrem $(\bowtie) \cdot$ H. U. Aamot • G. Brodal •

E. C. Strand · T. Torp · R. Dill-Macky • I. S. Hofgaard Norwegian Institute of Bioeconomy Research (NIBIO), Pb 115, 1431 Ås, Norway

e-mail: anne-grete.hjelkrem@nibio.no

E. C. Strand

Norwegian Agricultural Extension Service, Osloveien 1, 1430 Ås, Norway

S. G. Edwards

Crop and Environment Sciences Department, Harper Adams University, Shropshire, Newport TF10 8NB, UK

R. Dill-Macky

Department of Plant Pathology, University of Minnesota, 495 Borlaug Hall, 1991 Upper Buford Circle, St Paul, MN 55108, USA of $\mathrm{HT} 2+\mathrm{T} 2$ in oat grains. Our data show that adequate predictions of the risk of HT2 + T2 in oat grains at harvest can be achieved, based upon weather data observed during the growing season. Humid and cool conditions, in addition to moderate temperatures during booting, were associated with increased HT2 + T2 accumulation in harvested oat grains, whereas warm and humid weather during stem elongation and inflorescence emergence, or cool weather and absence of rain during booting reduced the risk of HT2 + T2 accumulation. Warm and humid weather immediately after flowering increased the risk, while moderate to warm temperatures and absence of rain during dough development, reduced the risk of HT2 + T2 accumulation in oat grains. Our data indicated that HT2 + T2 contamination in oats is influenced by weather conditions both pre- and post-flowering. These findings are in contrast with a previous study examining the risk of deoxynivalenol contamination in oat reporting that toxin accumulation was mostly influenced by weather conditions from flowering onwards.

Keywords Fusarium langsethiae Prediction model . Phenological windows $\cdot$ Spearman rank correlation coefficient

\section{Introduction}

High concentrations of HT-2 toxin (HT2) and T-2 toxin (T2), primarily produced by Fusarium langsethiae (Edwards et al. 2012; Torp and 
Nirenberg 2004; Torp and Langseth 1999), are occasionally detected in Norwegian oat grains (Norwegian Scientific Committee for Food Safety 2013). These mycotoxins are closely related (HT2 is a deacetylated form of T2), and normally co-occur (Hofgaard et al. 2016a; Edwards 2009; Langseth and Rundberget 1999; Xu et al. 2014). As the documentation on the occurrence of HT2 and T2 (HT2 + T2) toxins is still scarce, the European Commission (2013) has only set indicative levels for the sum of $\mathrm{HT} 2+\mathrm{T} 2$ in cereals and cereal products. These levels are not feed or food safety levels, however when concentrations are detected above these levels investigations should examine the factors leading to the presence of $\mathrm{HT} 2+\mathrm{T} 2$ toxins.

Early predictions of the risk of high HT2 + T2 levels in grain would be important for regulatory authorities and to allow industry to limit food and feed safety problems. By identifying the main variables that influence mycotoxin accumulation and their interactions, a better understanding of the accumulation of these mycotoxins will be achieved and a prediction model can be developed.

The understanding of the epidemiology of $F$. langsethiae and variables influencing the development of HT2 + T2 toxins is increasing, but still limited (Imathiu et al. 2013). The accumulation of HT2 + T2 in $F$. langsethiae infested oats in the UK has been associated with warm and wet weather conditions before anthesis (Opoku et al. 2013). Similar associations were found by $\mathrm{Xu}$ et al. (2014), with a positive relationship between the HT2 + T2 content in harvested oat grains and warm and wet conditions during early May (before anthesis) and dry conditions thereafter. Edwards (2017) combined data from 2002 to 2008 and found a negative relationship with late summer rainfall, indicating that drier conditions in July and August resulted in increased HT2 + T2. In an empirical model developed in the UK to predict $\mathrm{HT} 2+\mathrm{T} 2$ content in harvested oat grains, the authors suggested the use of growth stages instead of date as an important model improvement ( $\mathrm{Xu}$ et al. 2014). In addition to weather conditions, agronomic practices (organic or conventional), previous crop, tillage and oat variety have been shown to significantly influence HT2 + T2 accumulation in oat grains (Brodal et al. 2016; Edwards 2009).

In contrast to the large number of studies examining the variables that influence Fusarium graminearum infection and the accumulation of deoxynivalenol (DON) in cereal grains (e.g. Giroux et al. 2016; Andersen et al. 2015; Xu et al. 2013; Gourdain et al. 2011; De Wolf et al. 2003), only few investigations have been conducted on the epidemiology of F. langsethiae and HT2 + T2 accumulation. Oats are most susceptible to infection by $F$. graminearum during flowering (Tekle et al. 2012). By contrast, infection by $F$. langsethiae, is assumed to occur prior to flowering (Opoku et al. 2013). The weather conditions that influence the accumulation of HT2 $+\mathrm{T} 2$ in oats are also reported to differ from those observed to influence DON accumulation (Xu et al. 2014). Furthermore, no positive associations have been detected between the concentration of HT2 $+\mathrm{T} 2$ and DON, or between the Fusarium species that produce these mycotoxins in oats (Hofgaard et al. 2016a; Fredlund et al. 2013; Edwards 2009), indicating that the environmental requirements for successful infection and subsequent mycotoxin production in oats differs between these two fungal species.

In contrast to $F$. graminearum, where ascospores facilitate rapid and wide dispersal of inoclum, no sexual stage is known for $F$. langsethiae and the source of inoculum is still unknown. F. langsethiae seems to be more locally dispersed, and, compared to $F$. graminearum, only limited amounts of $F$. langsethia DNA has been detected in spore traps (Hofgaard et al. 2016b). Significant differences in the level of $F$. langsethiae infection of oat plots have been observed between experimental plots within a single field (Parikka et al. 2007).

The objective of this study was to identify associations between the content of HT2 + T2 in harvested oat grains and weather conditions at specific oat growth stages. Growth stage intervals (phenology windows), such as tillering, heading/flowering and senescence, were first estimated for oat crops grown in 188 farmer fields. Spearman rank correlations were then calculated between the HT2 + T2 content of the oat grains harvested from those fields and selected weather variables within each phenology window. Then, the most important weather variables were used in the development of an empirical model to predict the risk of HT2 $+\mathrm{T} 2$ accumulation in oat grains. Our ultimate goal was to develop a model that can be used by the Norwegian authorities and industry to identify grain lots with potential food and feed safety problems. 


\section{Materials and methods}

Oat samples

Oat grain samples, ca. $1 \mathrm{~kg}$, were collected at farms or at delivery points of oats from farmers' fields across cereal producing districts in Norway from 2004 to 2013. Samples were processed and stored according to Aamot et al. (2012), except for samples collected after 2009, where a sub-sample of $200 \mathrm{~g}$ was taken from the initial sample, ground using a high speed rotor mill (ZM 200, Retsch, Haan, Germany) fitted with a $1 \mathrm{~mm}$ sieve prior to storage.

In order to ensure that inoculum of fungal species producing $\mathrm{HT} 2+\mathrm{T} 2$ were present at all the locations included, only fields where the harvested grain samples had a HT2 + T2 concentration above the limit of detection (LOD) were included in the study. The final dataset consisted of samples from 188 oat fields in South-East Norway, with $92 \%$ of the samples collected within three important oat producing counties (27\% from Akershus, $14 \%$ from Østfold and 51\% from Hedmark). Most samples were collected in 2006 (17\%), 2007 (17\%), 2008 (14\%), 2010 (17\%) and $2012(15 \%)$.

\section{Mycotoxin analysis}

Of the 188 samples collected, 29 of the samples were analysed by LC-MS/MS method at the Institute of Sciences of Food Production (ISPA) where the HT2 + T2 LOD was equal to the limit of quantification (LOQ) of $23 \mathrm{\mu g} \mathrm{kg}^{-1}$ (Hofgaard et al. 2016a). A further 124 samples were analysed at NIBIO with an LC-MS/MS method where the LOD (LOD $=$ LOQ) was $23 \mu \mathrm{g} \mathrm{kg}^{-1}$ for the sum of HT2 and T2, as described in the method published in Aamot et al. (2013). However, in the present study HT2 was detected as an ammonia adduct of $\mathrm{m} / \mathrm{z} 442.20$ with the product ions $\mathrm{m} / \mathrm{z} 263.20$ and 215.14 . The final 35 samples were analysed with an ELISA method (AgraQuant ${ }^{\circledR}$ T2/HT2 Assay, Romer Labs ${ }^{\circledR}$, Tulln, Austria). The ELISA analysis was performed according to the manufacturer's instructions, except for the sample extraction. In our study sample extractions were done by adding $25 \mathrm{ml}$ of $70 \%$ methanol:distilled water $(v / \mathrm{v})$ to $5 \mathrm{~g}$ of the ground sample. The mixture was shaken vigorously for $3 \mathrm{~min}$, centrifuged for $1 \mathrm{~min}$ at $1811 \times \mathrm{g}$, and the supernatant was diluted $1+9$ with distilled water.
Finally an additional dilution of $1+1$ with $7 \%$ methanol: distilled water $(v / \mathrm{v})$ was made. Using this method we obtained a LOD of $120 \mathrm{\mu g} \mathrm{kg}^{-1}$ and a LOQ of $250 \mu \mathrm{g} \mathrm{kg}^{-1}$. For samples with a HT2 + T2 content above the LOD but below the LOQ, a value of LOQ/6 (European Commission 2003) was used.

\section{Weather data}

Weather data was collected from weather stations provided by Agrometeorology Norway (2016). Daily and hourly weather records of air temperature two meters above ground level $\left(\mathrm{T} ;{ }^{\circ} \mathrm{C}\right)$, precipitation $(\mathrm{P} ; \mathrm{mm})$ and relative humidity $(\mathrm{RH} ; \%)$ were used. For each grain sample, data were collected from the nearest weather station. Altogether, data from 20 different weather stations were used. Only samples from farms within $20 \mathrm{~km}$ (mean distance of $8.3 \mathrm{~km}$ ) from a weather station were included in the analysis.

Vapour pressure deficit (vpd; $\mathrm{kPa}$ ) is defined as the difference between the amount of moisture in the air and the moisture the air can hold when saturated. Saturated vapour pressures were estimated from measured air temperatures according to Goff and Gratch (1946), as is recommended by the World Meteorological Organisation (2012). The actual vapour pressure was derived from the estimated saturated vapour pressure and the measured RH (Perry and Green 1997). For example, an air temperature of $15{ }^{\circ} \mathrm{C}$ and a $\mathrm{RH}$ of $90 \%$ gives a vpd of $0.17 \mathrm{kPa}$, while, at the same temperature, a $80 \% \mathrm{RH}$ gives a vpd of $0.34 \mathrm{kPa}$ and a $70 \% \mathrm{RH}$ gives a vpd of $0.51 \mathrm{kPa}$.

Association between HT2 + T2 content and weather conditions

The BBCH scale was used to define plant growth stages (GS) (Lancashire et al. 1991), and dates for all growth stages from sowing to harvest were estimated for each grain sample by using the Oat Phenology Model (Hjelkrem et al. 2017). For the further analysis, the dataset for each grain sample was separated into ten intervals reflecting the different plant developmental stages (phenology windows). The phenology windows were selected in order to include growth stages that correspond to germination/seedling growth (GS 0-20), tillering (GS 20-30), stem elongation (GS 30-40), booting (GS 40-50), inflorescence emergence (GS 50-55), 
heading/flowering (GS 55-70), milk development (GS 70-75), late milk (GS 75-80), dough development (GS 80-90) and senescence (GS 90-95). For each grain sample, data for air temperature, precipitation and relative humidity, recorded at the nearest weather station, was summarised for each predicted phenological window. Possible associations between the mycotoxin content of HT2 + T2 in harvested oat grains and the weather summarisations (variables) within each phenological window, were calculated for the whole data set (188 grain samples) using the Spearman rank correlation coefficient (Spearman 2010). The Spearman rank correlation coefficient measures the association between two ranked variables, and it was used due to the non-normal distribution of data, which included a number of outliers with high HT2 + T2 values. The weather variables, were mainly selected based upon previous studies on variables influencing Fusarium development or mycotoxin accumulation in cereals (Xu et al. 2014; Kriss et al. 2010).

Prognosis system for identification of oat grain lots with HT2 + T2 levels exceeding acceptable limits

Discriminant analysis, with stepwise selection and leave-one-out cross-validation, was used in order to develop a model to forecast the risk of elevated levels of HT2 + T2 in harvested oats. A rigorous threshold value of $500 \mu \mathrm{g} \mathrm{kg}^{-1}$ was chosen for this study (the indicative level for unprocessed oats is $1000 \mu \mathrm{g} \mathrm{kg}^{-1}$ (European Commission 2013)). Weather variables that were significantly $(p<0.05)$ correlated with the HT2 + $\mathrm{T} 2$ content in oats at harvest were included in the model development. The stepwise procedure can be distorted by multicollinearity (Montgomery et al. 2001). Therefore, if two weather variables each have correlations greater than 0.9 , only the one with highest correlation to HT2 + T2 at harvest was used as the input variable to the stepwise selection procedure. Additionally, contrasting conditions were not accepted in the resulting model.

\section{Statistical methods}

SAS 9.4 was used for the discriminant analysis, with the functions 'stepdisc' and 'discrim', while all other calculations were performed using MATLAB (R2016b). The 'corr' function with type 'Spearman' was used to calculate the Spearman rank correlation coefficient. All other calculations performed in this study were written in script files.

\section{Results}

This study was performed in two parts. Initially, the weather conditions during phenological development, that were significantly associated with HT2 + T2 accumulation in harvested oat grains were identified, then, a mathematical model to predict HT2 + T2 accumulation in oat grains at harvest was developed.

Association between HT2 + T2 content and weather conditions

Among the 188 samples included in the dataset, the amount of HT2 + T2 detected varied from a maximum of $2998 \mu \mathrm{g} \mathrm{kg}^{-1}$ to the levels of detection (LOD). The median HT2 + T2 value was $199 \mu \mathrm{g} \mathrm{kg}^{-1}$, the mean $\mathrm{HT} 2+\mathrm{T} 2$ value was $372 \mu \mathrm{g} \mathrm{kg}^{-1}$ and the standard deviation of the mean was $468 \mu \mathrm{g} \mathrm{kg}^{-1}$. Nine percent of the samples contained HT2 + T2 levels above the indicative limit set for unprocessed oats $(1000 \mu \mathrm{g}$ $\mathrm{kg}^{-1}$ ), and $25 \%$ of the samples contained HT2 $+\mathrm{T} 2$ values higher than our more rigorous level of $500 \mu \mathrm{g}$ $\mathrm{kg}^{-1}$ used in this study. The same samples were also tested for DON contamination (Hjelkrem et al. 2017) and no significant $(p<0.05)$ relationship was observed between the concentrations of the two mycotoxins ( $\mu \mathrm{g}$ $\mathrm{kg}^{-1}$ oat grain) in an ordinal regression analysis (using the natural logarithm).

A total of 148 weather variables, based on air temperature, rainfall and relative humidity were summarised within each of the ten estimated phenology windows for all 188 oat fields included in this study. The weather variables used are given in the $e$ Xtra (Table S1). Table 1 presents the month (approximate time period), along with the daily mean (and $\mathrm{SD}$ of the mean), minimum and maximum daily and hourly air temperatures within each of the ten phenological windows across the 188 Norwegian oat fields examined. In this paper, these weather data are used as a reference when discussing prevalent weather according to Norwegian conditions.

Within each of the ten phenological windows, the Spearman rank correlation coefficient was calculated for the association between the HT2 + T2 content of harvested oat grain and each of the 148 different weather 


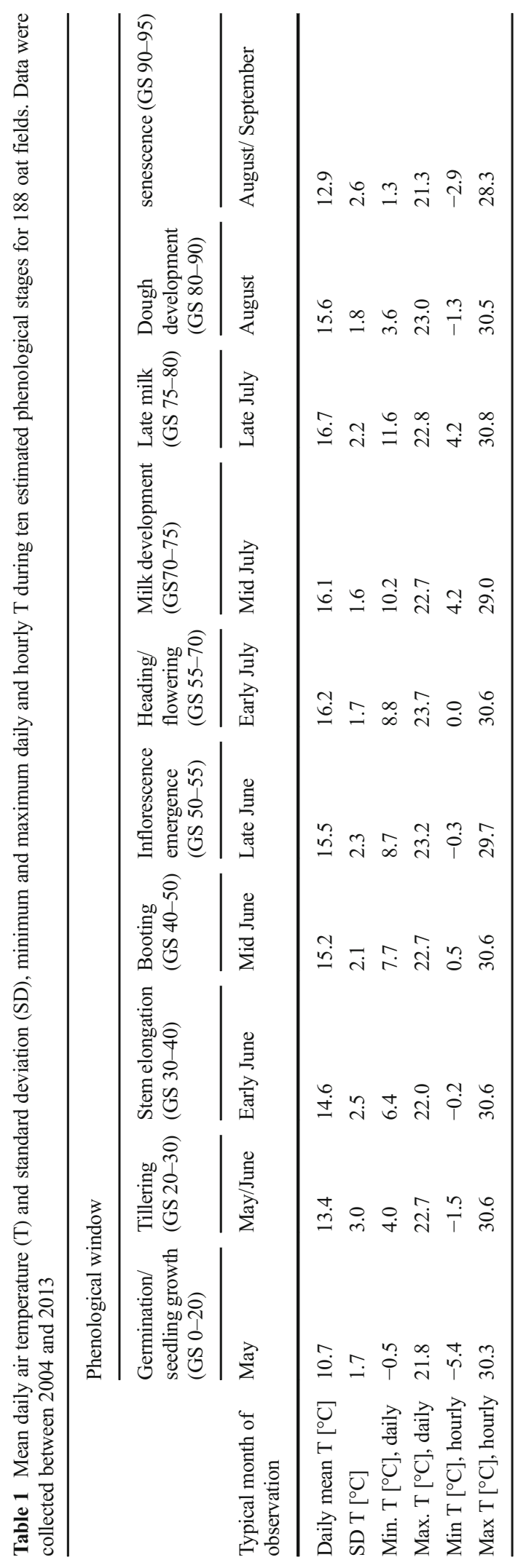

variables considered. Significant correlations between the HT2 + T2 content in harvested oat grains and the weather variables were found for all the phenology windows. Only selected significant correlations $(p<0.05)$ between HT2 + T2 in harvested oat grains and the weather variables for the phenological windows are presented in the text, though all the calculated correlations are given in Table $\mathrm{S} 1$ in the $e$-Xtra.

The associations between the HT2 + T2 content of harvested oat grains and the average daily air temperature, within the phenology windows are presented in Fig. 1a. A positive correlation was detected during germination/seedling growth $(r=0.26, p<0.001)$. By considering the daily number of hours with $\mathrm{T}$ in $[10$ 20) ${ }^{\circ} \mathrm{C}$ (equivalent to $10{ }^{\circ} \mathrm{C} \leq T<20^{\circ} \mathrm{C}$ ), positive correlations were detected for all phenological windows pre-flowering (from sowing to end of inflorescence emergence), with highest value observed during tillering $(r=0.37, p<0.001)$ (Table S1). The HT2 + T2 content at harvest was not correlated with average daily air temperature during heading/flowering (Fig. 1a). However, a positive correlation with HT2 + T2 content was detected during heading/flowering when considering the daily number of hours with $T \geq 10{ }^{\circ} \mathrm{C}(r=0.23$, $p=0.003$ ) (Table S1). Post-flowering, negative correlations were detected between HT2 + T2 contamination in harvested oat grains and average daily air temperature from late milk to harvest, with highest value observed during dough development $(r=-0.35, p<0.001)$ (Fig. 1a). Considering only the correlations between the HT2 + T2 content and the daily number of hours with $T<5{ }^{\circ} \mathrm{C}$ (Table S1), positive correlations were found for all phenological windows post-flowering (from milk development to harvest), with the highest value during dough development $(r=0.39, p<0.001)$.

The associations between HT2 + T2 contamination in harvested oat grains and average daily precipitation within the phenology windows of selected oat growth stages are given in Fig. 1b. Positive correlations were detected from tillering to the end of booting, with the highest value occurring during stem elongation $(r=0.30, p<0.001)$. A negative correlation was detected during heading/flowering $(r=-0.16, p=0.025)$, while no significant $(p<0.05)$ correlations with the average daily precipitation were detected post-flowering (Fig. 1b).

The associations between HT2 + T2 contamination in harvested oat grains and average daily relative humidity within the phenology windows of selected oat 
Fig. 1 The Spearman rank correlation coefficients, calculated between HT2 + T2 $(\mu \mathrm{g}$ $\mathrm{kg}^{-1}$ ) contamination in harvested oats and weather conditons, during estimated time-periods (phenology windows) of plant growth stages (BBCH scale). Asterisks indicate that the correlation is significant at $10 \%$ level (*) or $5 \%$ level (**). The weather conditions are based on air temperature $(\mathrm{T})$, precipitation $(\mathrm{P})$, relative humidity $(\mathrm{RH})$ and vapour pressure deficit (vpd)

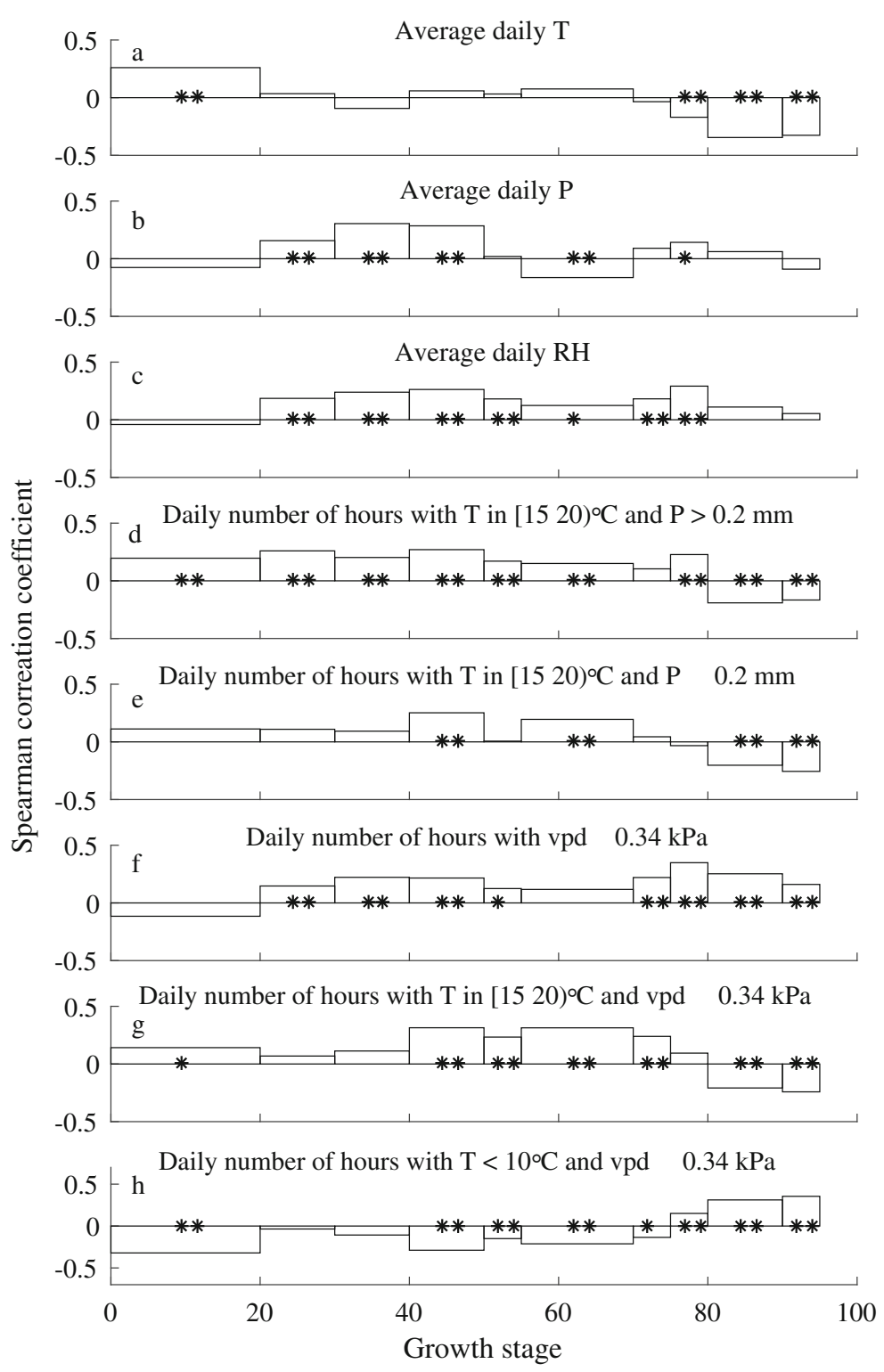

growth stages are given in Fig. 1c. Positive correlations were detected from tillering to the end of inflorescence emergence, with highest value observed during booting $(r=0.26, p<0.001)$. No significant $(p<0.05)$ correlation between HT2 + T2 and daily relative humidity was detected during heading/flowering. However, when considering the daily number of hours with $\mathrm{RH}$ in $[75$ 90)\% (Table S1), a positive correlation was detected $(r=0.21, p=0.005)$ during heading/flowering. Positive correlations were also detected between the HT2 + T2 content in harvested oat grains and the average daily relative humidity during the phenological windows milk development and late milk, with the highest value occurring during late milk $(r=0.29, p<0.001)$.

The associations between HT2 + T2 contamination in harvested oat grains and the daily number of hours with $\mathrm{T}$ in $\left[\begin{array}{ll}15 & 20\end{array}{ }^{\circ} \mathrm{C}\right.$ and precipitation $(P>0.2 \mathrm{~mm})$ within the phenology windows of selected oat growth stages are given in Fig. 1d. Positive correlations were detected for all phenological windows to the end of heading/flowering, with the highest value observed during booting $(r=0.27, p<0.001)$. A negative correlation was identified between the HT2 $+\mathrm{T} 2$ content at harvest and the daily number of hours with $T<10{ }^{\circ} \mathrm{C}$ and 
precipitation during heading/flowering $(r=-0.29, \mathrm{p}<$ 0.001) (Table S1). Negative correlations were detected between HT2 + T2 content and the daily number of hours with $\mathrm{T}$ in $\left[\begin{array}{ll}15 & 20\end{array}{ }^{\circ} \mathrm{C}\right.$ and precipitation during dough development $(r=-0.19, p=0.009)$ and senescence $(r=-0.17, p=0.030)$. Furthermore, when considering the daily number of hours with $\mathrm{T}<10{ }^{\circ} \mathrm{C}$ and precipitation for all post-flowering windows (Table S1), positive correlations were detected, with the highest value occurring during dough development $(r=0.40, p<0.001)$.

The associations between HT2 + T2 contamination in harvested oat grains and the daily number of hours with $\mathrm{T}$ in $[1520){ }^{\circ} \mathrm{C}$, and no precipitation $(P \leq 0.2 \mathrm{~mm})$ within the phenology windows, of selected oat growth stages are given in Fig. 1e with a positive correlation detected during booting $(r=0.25, p<0.001)$. Also, the correlations between HT2 $+\mathrm{T} 2$ content and the daily number of hours with $\mathrm{T}$ in $\left[\begin{array}{ll}10 & 20\end{array}{ }^{\circ} \mathrm{C}\right.$ and no precipitation (Table S1), were positive for the windows from sowing to stem elongation, with the highest value observed during tillering $(r=0.34, p<0.001)$. However, negative correlations were detected during germination/ seedling growth $(r=-0.30, p<0.001)$ and booting $(\mathrm{r}=$ $-0.30, p<0.001)$ between HT2 + T2 and the daily number of hours with $T<10{ }^{\circ} \mathrm{C}$ and no precipitation (Table S1). A positive correlation was detected between the HT2 + T2 contamination in harvested oat grains and daily number of hours with $\mathrm{T}$ in $[15,20){ }^{\circ} \mathrm{C}$ and no precipitation during the heading/flowering phenology windows $(r=0.20, p=0.007)$ (Fig. 1e). Negative correlations were detected between the HT2 + T2 content in harvested oat grains and the daily number of hours with $\mathrm{T}$ in $[15,20){ }^{\circ} \mathrm{C}$ and no precipitation for the postflowering phenology windows of dough development $(r=-0.20, p=0.005)$ and senescence $(r=-0.26$, $p<0.001$ ) (Fig. 1e).

The associations between HT2 + T2 contamination in harvested oat grains and the daily number of hours with humid weather, as defined by a low vapour pressure deficit ( $v p d \leq 0.34 \mathrm{kPa}$ ), within the phenology windows of selected oat growth stages are presented in Fig. 1f. Positive correlations were detected between HT2 + T2 content and daily number of hours with humid weather from tillering to the end of booting, with the highest values recorded during stem elongation ( $r=$ $0.22, p=0.002)$ and booting $(\mathrm{r}=0.22, p=0.003)$. No significant $(p<0.05)$ correlations with humid weather were detected during heading/flowering, although positive correlations were detected for the four postflowering phenology windows from milk development to the end of senescence, with highest value recorded during late milk $(r=0.35, p<0.001)$.

The associations between HT2 + T2 content in harvested oat grains and daily number of hours with $\mathrm{T}$ in $[1520){ }^{\circ} \mathrm{C}$ and humid weather $(\mathrm{vpd} \leq 0.34 \mathrm{kPa})$ within the phenology windows of selected oat growth stages are presented in Fig. 1g. Positive correlations were found around flowering, including in the four phenological windows from booting to end of milk development, with the highest value recorded during the booting $(r=0.31, p<0.001)$ and heading/flowering $(\mathrm{r}=0.31, \mathrm{p}<0.001)$ phenological windows. By contrast, negative correlations were detected during dough development $(r=-0.21$, $p=0.004)$ and senescence $(r=-0.24, p=0.002)$.

The associations between HT2 + T2 contamination in harvested oat grain and the daily number of hours with $T<10{ }^{\circ} \mathrm{C}$ and humid weather $(\mathrm{vpd} \leq 0.34 \mathrm{kPa})$ within the phenology windows of selected oat growth stages are presented in Fig. 1h. A negative correlation was detected during the germination/seedling growth ( $r=-0.32, p<0.001$ ), and from booting to the end of heading/flowering, with the highest value recorded during booting $(r=-0.29 p<0.001)$. Conversely, positive correlations were apparent from late milk to senescence, with the highest value detected during the senescence window $(r=0.35, p<0.001)$.

Prognosis system for identification of oat grain lots with HT2 + T2 levels exceeding acceptable limits

To develop a prognosis system for the identification of oat grain lots with a high risk of having their HT2 + T2 toxin levels exceed the indicative levels for T-2 and HT2 toxin in cereal and cereal products, according to Commission Recommendation 2013/165/EU, a mathematical model to predict the risk of HT2 + T2 contamination of oat grains was developed. A rigorous threshold value of $500 \mu \mathrm{g} \mathrm{kg}^{-1}$ grain was chosen in this study, given that the current indicative level for unprocessed oats is $1000 \mu \mathrm{g} \mathrm{kg}^{-1}$. All weather variables with a significant $(p<0.05)$ effect on HT2 + T2 accumulation and with pair-wise correlations to each other of less than 0.9 (Table S1), were considered in the development of the model. Consequently, only 112 weather variables (Table S1) were utilised in model development. The model was developed and evaluated using discriminant 
analysis with stepwise selection and leave-one-out cross-validation. The final model consisted of seven weather variables and is given in Eq. 1.

$$
\begin{aligned}
M= & 9.15-0.90 c_{1}+0.38 d_{1} \\
& +0.31 d_{2}-0.60 d_{3}-0.48 e_{1}+7.86 g_{1}-0.55 i_{1}
\end{aligned}
$$

The model forecasts a risk of elevated HT2 + T2 levels if the model output for ' $M$ ' is greater than zero. The model variable $c_{l}$ is daily number of hours with $\mathrm{T}$ in [15 20) ${ }^{\circ} \mathrm{C}$ and $\mathrm{RH}>75 \%$ during stem elongation. The model variables $d$ are a number of weather variables during the phenological window booting, including the daily number of hours with $T<12{ }^{\circ} \mathrm{C}$ and $\operatorname{vpd} \leq$ $0.34 \mathrm{kPa}\left(d_{1}\right)$, daily number of hours with $\mathrm{T}$ in $[10$, 20) ${ }^{\circ} \mathrm{C}\left(d_{2}\right)$ and daily number of hours with $T<15{ }^{\circ} \mathrm{C}$ and $P \leq 0.2 \mathrm{~mm}\left(d_{3}\right)$. The model variable $e_{1}$ is the daily number of hours with $\mathrm{T}$ in $[15,20){ }^{\circ} \mathrm{C}$ and $\mathrm{vpd} \leq$ $0.17 \mathrm{kPa}$ during inflorescence emergence. The model variable $g_{1}$ is the daily number of hours with $\mathrm{T}$ in $[15$, 20) ${ }^{\circ} \mathrm{C}$ and vpd $\leq 0.51 \mathrm{kPa}$ during milk development, while the variable $i_{1}$ is the daily number of hours with $T \geq 12{ }^{\circ} \mathrm{C}$ and $\mathrm{P} \leq 0.2 \mathrm{~mm}$ during dough development.

A contingency table (Table 2) of the model performance with our threshold value of $500 \mathrm{\mu g} \mathrm{kg}^{-1}$ was created based on the leave-one-out cross-validation. The results indicate a specificity (observed and estimated values lower than $500 \mu \mathrm{g} \mathrm{kg}^{-1}$ ) of $60 \%$ and a sensitivity of $22 \%$ (observed and estimated values higher than $500 \mu \mathrm{g} \mathrm{kg}^{-1}$ ). Thus, in the model $3 \%$ of the observations were incorrectly estimated to be lower (false negatives), and $15 \%$ to be higher (false positives) than $500 \mu \mathrm{g} \mathrm{kg}^{-1}$, respectively. Additionally, the risk of $\mathrm{HT} 2+\mathrm{T} 2$ toxin levels exceeding $500 \mu \mathrm{g} \mathrm{kg}^{-1}$ oat was estimated for all observations, resulting in a similar sensitivity and a slightly higher specificity (61\%). Thus, five (3\%) of the observations were incorrectly estimated to less than $500 \mu \mathrm{g}$

Table 2 The contingency table of model performance following the cross-validation of results from the prediction model for identification of oat grain lots with combined HT-2 and T-2 toxin levels $\mathrm{kg}^{-1}$, and of these five, two were in reality higher than the indicative level for unprocessed oats $\left(1000 \mu \mathrm{g} \mathrm{kg}^{-1}\right)$.

The model generally predicted an increased risk of elevated levels of HT2 + T2 toxins in oats from fields with humid conditions combined with air temperatures cooler than average for Norway $\left(T<12^{\circ} \mathrm{C}\right)$ or when the prevailing air temperatures were around average ( $\mathrm{T}$ in $[10,20){ }^{\circ} \mathrm{C}$ ) during booting. Relatively warm temperatures ( $\mathrm{T}$ in $[1520)^{\circ} \mathrm{C}$ ) and humid conditions during milk development additionally increased the toxin risk (Fig. 2). The model predicted a decreased risk of elevated levels of $\mathrm{HT} 2+\mathrm{T} 2$ toxins in oats from fields with humid conditions and warmer than average temperatures ( $\mathrm{T}$ in $[15,20)$ ${ }^{\circ} \mathrm{C}$ ) during stem elongation and inflorescence emergence

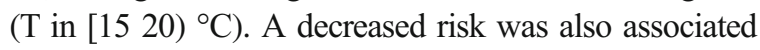
with cooler than average temperatures $\left(T<15^{\circ} \mathrm{C}\right)$ and no rain $(P \leq 0.2 \mathrm{~mm})$ during booting. Additionally, the model predicted a decreased risk of HT2 $+\mathrm{T} 2$ toxin when temperatures were around and/or warmer than average $\left(T>12{ }^{\circ} \mathrm{C}\right)$ and with no rain during dough development.

\section{Discussion}

Elevated HT2 + T2 concentrations in oat grains have been reported in Norway (Hofgaard et al. 2016a), Sweden (Fredlund et al. 2013), Finland (Nathanail et al. 2015), Switzerland (Schirdewahn et al. 2016) and in the UK (Edwards 2009). The goal of this study was to identify possible associations between weather conditions at specific growth stages of oats and the content of HT2 + T2 in harvested oat grains. Some of the important weather variables were then included in an empirical model to predict the risk of elevated levels of HT2 + T2 in oat grains at harvest.

To identify associations between the HT2 + T2 content of harvested oat grains and weather conditions

exceeding a chosen level of $500 \mu \mathrm{g} \mathrm{kg}^{-1}$, displaying the relationship between the true observations and the predicted model outcome

\begin{tabular}{lllll}
\hline & & & & \\
\cline { 3 - 4 } & & $<500 \mu \mathrm{g} \mathrm{kg}^{-1}$ & $\geq 500 \mu \mathrm{kg}^{-1}$ & $\mathrm{Total}^{-1}$ \\
\hline Predicted model outcome & $<500 \mu \mathrm{g} \mathrm{kg}^{-1}$ & $60 \%(113)$ & $3 \%(6)$ & $63 \%(119)$ \\
& $\geq 500 \mu \mathrm{g} \mathrm{kg}^{-1}$ & $15 \%(28)$ & $22 \%(41)$ & $37 \%(69)$ \\
& Total & $75 \%(141)$ & $25 \%(47)$ & $100 \%(188)$ \\
\hline
\end{tabular}




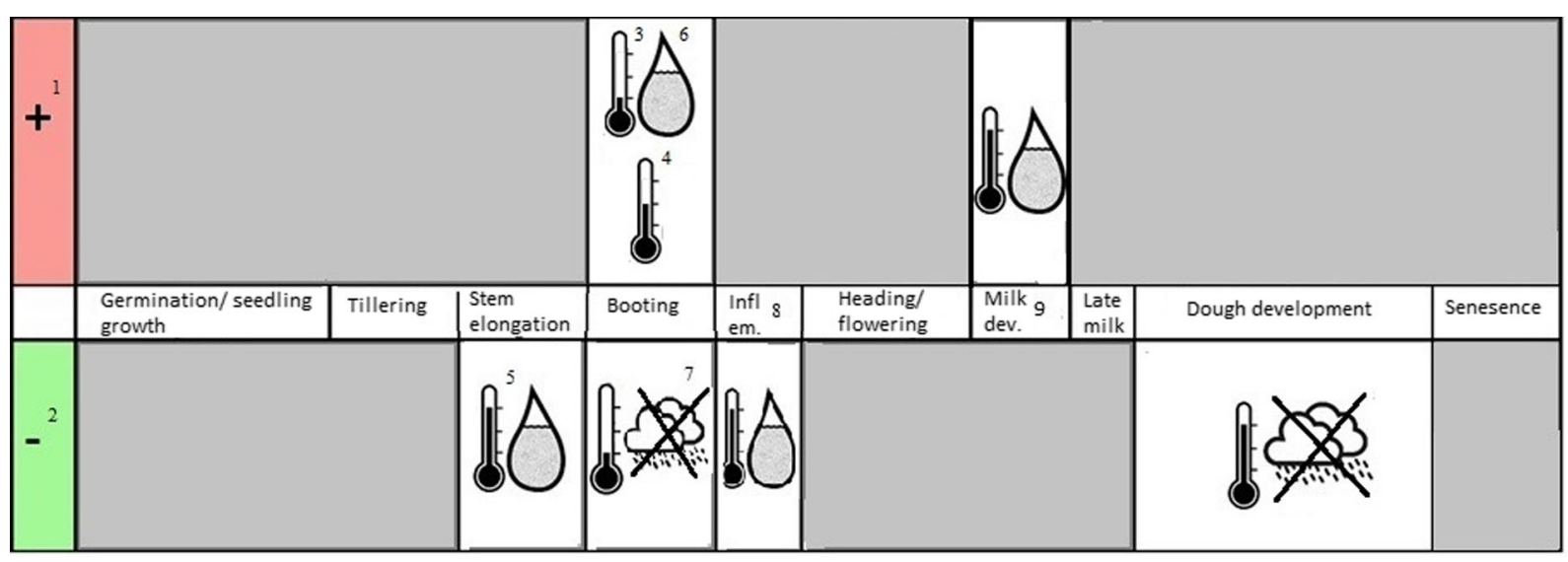

Fig. 2 A visualization of a prediction model developed for the identification of oat grain lots with risk of HT2 + T2 toxin levels exceeding a chosen level of $500 \mu \mathrm{g} \mathrm{kg}^{-1}$, based on the weather data prevailing during ten different phenological windows identified between sowing and harvest. ${ }^{1}$ Symbols displayed above phenological windows indicate conditions associated with

within different growth stages, we defined the time periods for each of ten specific growth stages in 188 oat fields and analysed the harvested grain samples for their HT2 + T2 content. Predicted growth stages, as opposed to the number of days from sowing, were chosen because the relationship between number of days from sowing and phenological development in oats had been shown to be quite poor (Hjelkrem et al. 2017). Furthermore, the use of phenological growth stages has previously been proposed as an improvement when modelling the accumulation of HT2 + T2 in oats (Xu et al. 2014). Our approach is based on the window-pane methodology (Coakley et al. 1982; Kriss et al. 2010) that is used to quantify the importance of environmental variables within temporal windows. A similar mathematical model, designed to predict growth stages of oats based on sowing time and weather conditions, was recently developed to quantify the relationship between weather conditions and DON accumulation in Norwegian oats (Hjelkrem et al. 2017). In the present study, we identified possible associations between the occurrence of HT2 + T2 toxins in harvested oat grains and weather conditions between sowing and harvest.

\section{Association between HT2 + T2 content and weather conditions pre-flowering}

For the 188 fields included in this study, the HT2 + T2 content of the harvested oats was clearly influenced by the weather conditions prevailing during the pre- increased risk of HT2+T2 accumulation; ${ }^{2}$ Symbols displayed below phenological windows indicate conditions associated with decreased risk of HT2+T2 accumulation; ${ }^{3} \mathrm{Cool}$ air temperature for that period; ${ }^{4}$ Moderate air temperatures for that period; ${ }^{5}$ Warm temperatures for that period; ${ }^{6}$ Humid conditions; ${ }^{7}$ No rain; ${ }^{8}$ Inflorescence emergence; ${ }^{9}$ Milk development

flowering phenological growth stages. Our model, developed to predict risk of HT2 + T2 in harvested oat grains, included five weather variables collected in the period prior to flowering. Likewise, models developed in the UK to predict concentrations of HT2 + T2 in oat grains included mainly pre-flowering variables $(\mathrm{Xu}$ et al. 2014). In contrast, a model developed to predict the risk of DON contamination in harvested oat grains in Norway included only three out of the eight weather variables examined in the period prior to flowering (Hjelkrem et al. 2017). Fusarium langsethiae is regarded as the main $\mathrm{HT} 2+\mathrm{T} 2$ producer in oats in both Norway and UK (Hofgaard et al. 2016a; Edwards et al. 2012), whereas F. graminearum is the most important DON producer in Norwegian oats (Hofgaard et al. 2016a). The differences between the prediction models for HT2 + T2 versus DON contamination in oats may imply that the weather conditions critical for toxin development in oats differs between the HT2 + T2-producer $F$. langsethiae and the DON-producer $F$. graminearum. This likely reflects differences in the biology of these fungi, such as the timing and/or growth stage of the initial infection or differences in weather requirements for inoculum production and dispersal.

According to the Spearman rank correlation study, the risk of HT2 + T2 contamination was generally greater in oat grains from fields with wet/humid weather conditions in the pre-flowering period. Likewise, the mathematical model we developed predicted an increased risk of HT2 $+\mathrm{T} 2$ accumulation in oats growing 
under humid during booting. In accordance with our study, Xu et al. 2014 also reported that wet conditions pre-flowering were important in predicting the risk of HT2 + T2 in UK oats. Additionally, Opoku et al. 2013 observed higher $F$. langsethiae infection levels, and subsequent mycotoxin production, in seasons with humid weather in the week prior to GS59 (end of heading). Furthermore, Opoku et al. 2013 observed a high content of $F$. langsethiae DNA in oat plants around GS59 that suggested infection by $F$. langsethiae occurs during head emergence and before flowering. Together these studies suggest that weather conditions pre-flowering influence the initial $F$. langsethiae infection and subsequent mycotoxin production.

While our mathematical model predicted an increased risk of elevated HT2 + T2 levels with humid and cool $\left(T<12{ }^{\circ} \mathrm{C}\right)$ temperatures, as well as with moderate temperature conditions ( $\mathrm{T}$ in $[10,20){ }^{\circ} \mathrm{C}$ ) during booting, it also predicted a reduced risk of the accumulation of these toxins with humid and warm ( $T$ in [15 20) ${ }^{\circ} \mathrm{C}$ ) weather conditions during stem elongation and inflorescence emergence. Temperature influences the infection, growth and mycotoxin production by F. langsethiae (Nazari et al. 2014; Kokkonen et al. 2012; Medina and Magan 2011). Fusarium langsethiae is recognized to have a slower growth rate than other Fusarium species including; F. sporotrichioides, F. poae and $F$. kyushuense, although all four species have much the same optimum temperature (Torp and Nirenberg 2004). Fusarium graminearum has a significantly faster growth rate in vitro than $F$. langsethiae at $20{ }^{\circ} \mathrm{C}$ (Shakery 2012). Hofgaard et al. 2016a observed slightly lower risk of elevated HT2 + T2 levels in F. langsethiae contaminated grains when $F$. graminearum is additionally present. Therefore, we hypothesize that humid and warm weather conditions favour faster growing Fusarium species, such as F. graminearum, that outcompete F. langsethiae, reducing the risk of elevated HT2 + T2 in the grain. Additionally, our risk model predicted a decreased risk of elevated HT2 + T2 levels with dry (no rain) and cool $\left(T<15^{\circ} \mathrm{C}\right)$ conditions during booting. If initial $F$. langsethiae infection of oats takes place around booting, dry conditions may reduce the growth of F. langsethiae and thereby reduce the ability of this fungus to infect the oat plants during this period.

Our data, along with those presented in other studies, indicate that HT2 + T2 contamination in oats is clearly influenced by the weather conditions pre-flowering, which may suggest that the initial infection of
F. langsethiae takes place during this growth period. By contrast, $F$. graminearum is considered to infect oat at, or soon after, flowering (Tekle et al. 2012), and the risk of DON contamination has been reported to be little influenced by the weather conditions during growth stages prior to flowering (Hjelkrem et al. 2017).

Association between HT2 + T2 content and weather conditions at heading/flowering

Our risk model did not include any variables associated with weather conditions during heading/ flowering. Likewise, the eight selected models, developed by Xu et al. 2014 to predict the concentration of $\mathrm{HT} 2+\mathrm{T} 2$ in UK oats did not include any weather variables during early June, a period that would typically correspond to the flowering time of oat crops in the UK. In contrast, weather conditions during heading/flowering seem to have a high influence on the DON-risk in Norwegian oats (Hjelkrem et al. 2017). Spray inoculations with $F$. graminearum at different growth stages have shown that oat is highly susceptible to $F$. graminearum during flowering (Tekle et al. 2012), and positive associations were detected between DON accumulation and rain during the heading/flowering in our previous study (Hjelkrem et al. 2017). The negative association detected between HT2 + T2 accumulation in oat grains and rain during the heading/flowering period observed in our Spearman rank correlation study supports the assumption of a different timing of initial infection by $F$. langsethiae compared to $F$. graminearum. This is further supported by the finding of $\mathrm{Xu}$ et al. 2014, that reported a positive relationship between the HT2 + T2 concentration at harvest and dry conditions from late May onwards (including the heading/flowering period) in UK oats. We further hypothesize that if the weather conditions during flowering favour $F$. graminearum infection this pathogen may outcompete $F$. langsethiae, and in so doing reduce the risk of elevated HT2 + T2 levels.

Despite finding that none of the variables in our model were associated with weather conditions during the heading/flowering, the Spearman rank correlations indicate an association between $\mathrm{HT} 2+\mathrm{T} 2$ accumulation in oats and warm (warmer than the average of $16^{\circ} \mathrm{C}$ for that period, Table 1) weather conditions during the heading/flowering period. This finding is in line with a study by Bernhoft et al. 2012 who reported a positive 
relationship between $F$. langsethiae and the mean July temperature (typically corresponding to the flowering time of oats in Norway). Fusarium langsethiae has an optimum growth rate between $20^{\circ} \mathrm{C}$ and $24^{\circ} \mathrm{C}$ (Imathiu et al. 2016, Nazari et al. 2014). This suggests that increased temperatures, within the range of temperatures normally observed in Norway and UK, will stimulate the growth of $F$. langsethiae, thereby increasing the risk of elevated HT2 + T2 levels in oats.

Association between HT2 + T2 content and weather conditions post-flowering

Both the Spearman rank correlation and the risk model developed for HT2 + T2 accumulation in this study showed that weather conditions during the postflowering period, from milk development to harvest, had an impact on HT2 + T2 accumulation in oats.

Our risk model predicted an increased risk of elevated HT2 + T2 levels with moderately humid to humid and warm ( $\mathrm{T}$ in $[1520)^{\circ} \mathrm{C}$ ) conditions during milk development. In a field study of oats in Norway, Hofgaard et al. 2016b found that the amount of Fusarium spp. DNA in air samples increased during warm and rainy periods. In the same study, F. langsethiae DNA was detected in air samples from oat fields collected four weeks after heading and later (Hofgaard et al. 2016b), corresponding to oat growth stages late milk to early dough development according to our oat phenology model (Hjelkrem et al. 2017). The increased risk of elevated HT2 + T2 levels with humid and warm conditions during milk development, as identified by our risk model, may be related to an increased risk of $F$. langsethiae growth and/or dispersal under such conditions.

During dough development, our risk model predicted a negative association between HT2 + T2 accumulation in oats and moderate to warm $\left(T>12^{\circ} \mathrm{C}\right)$ temperatures and dry (no rain) conditions. Accordingly, Kokkonen et al. 2012 showed that high water activity is an important variable for production of $\mathrm{HT} 2+\mathrm{T} 2$ by $F$. langsethiae. The reduced risk with dry conditions could be a result of conditions unfavorable for the production of HT2 + T2 by F. langsethiae. Oppositely, $\mathrm{Xu}$ et al. 2014 reported a positive relationship between HT2 + T2 at harvest and dry conditions from late May (i.e. panicle emergence) and onwards in UK oats.

Close to harvest, the Spearman rank correlation study showed a positive association between accumulation of
HT2 + T2 and humid weather conditions. Bernhoft et al. 2012 also identified an increased risk of HT2 in oat when high humidity was recorded immediately before harvest. Humid weather may increase the likelihood of harvesting wet grain and thus increase the chance that F. langsethiae continues to be metabolic active after harvest, and produce additional HT2 and T2 in storage (Medina and Magan 2011).

In our study, weather conditions during the postflowering period, from milk development to harvest, had a impact on HT2 + T2 accumulation. We speculate that the weather conditions that are associated with increased risk of elevated HT2 + T2 levels are associated with increased sporulation, mycelial growth and increased production of HT2 and T2 by F. langsethiae in oats. However, further studies are needed to fully understand how the dispersal and development of F. langsethiae, as well as the accumulation of HT2 + T2, is affected by the environmental conditions during post-flowering.

Summarizing comments on the relationship between weather conditions and HT2 + T2 content

The association between weather conditions during oat development in Norway and HT2 + T2 accumulation in harvested oat grains differed between the phenological windows examined in our study. Wet/humid and moderate warm conditions prior to flowering were associated with increased HT2 + T2 accumulation in grain, whereas low or higher than normal air temperatures during this same period were associated with reduced $\mathrm{HT} 2+\mathrm{T} 2$. These results concur with previous studies that indicate that the pre-flowering weather conditions are critical for HT2 + T2 accumulation in oats (Opoku et al. 2013). Warm/humid weather after flowering, and $\mathrm{cool} /$ humid weather close to harvest increased the risk of elevated HT2 + T2 levels, whilst warm temperatures and no rain during dough development reduced the risk of HT2 + T2 accumulation in oat grains. These results show that weather conditions during the post-flowering period, from milk development to harvest, may also have an impact on HT2 + T2 accumulation. Weather conditions during heading/flowering appeared to be of less importance in the accumulation of these toxins in oat. Weather conditions during the pre- and postflowering periods may directly influence the ability of $F$. langsethiae to infect, spread and produce toxins in oat grains. However, weather conditions during these 
periods may also impact on the competition between F. langsethiae and other microorganisms, and may influence the host plants response to an infection, and the subsequent production of HT2 + T2 toxins. To understand the accumulation of HT2 + T2 in oats, more knowledge is needed as to how the weather influences the pathogen, its competitors, and the hosts.

Prognosis system for identification of oat grain lots with HT2 + T2 levels exceeding acceptable limits

A rigorous threshold value for the HT2 $+\mathrm{T} 2$ content of $500 \mu \mathrm{g} \mathrm{kg}^{-1}$ grain was selected in this study, given that the current indicative limits for unprocessed oats is set at $1000 \mathrm{~g} \mathrm{~kg}^{-1}$ (The European Commission 2013). Only $9 \%$ of the observed data were above the indicative limit whereas $25 \%$ of our data points were above the more rigorous threshold we utilized. Utilizing a lower threshold value in our study meant that we had a greater proportion of data points with a high risk of elevated HT2 + T2 contamination and minimized the number of samples that falsely predicted to have no risk of high HT2 + T2 contamination by our model. The model developed in this study ultimately predicted the risk of elevated HT2 + T2 levels adequately, with $83 \%$ of the observations correctly estimated as being lower or higher than the rigorous threshold we used. Among the samples incorrectly estimated, only $1 \%$ of the samples were incorrectly identified as being of "no risk". The model developed in this study relied on closely predicted oat growth stages. In a study by Giroux et al. 2016, nine models were evaluated for their ability to predict the risk of elevated levels of DON in wheat, using both predicted and observed phenological stages of the host plant. The precision of their model was higher when using observed growth stages compared to predicted growth stages. Thus, an improvement of our model may be achieved by using observed (vs. predicted) growth stages. Although not examined in our study, it is evident that agronomic variables, such as previous crop, cultivation and variety, substantially influence the concentration of HT2 + T2 in oat grains (Brodal et al. 2016; Edwards 2009). The model developed in our study to predict the risk of elevated HT2 + T2 levels in spring oats, was developed and validated for Norwegian weather conditions only. However, after validation of the model with local data, this model may be useful in other regions where spring oat is grown.
Our model, developed to predict risk of elevated $\mathrm{HT} 2+\mathrm{T} 2$ levels in harvested oat grains, included many pre-flowering variables, no variables during flowering, and a few variables during the postflowering and senescence periods. This is in contrast to the model developed to predict DON-risk in Norwegian oats, in which the weather conditions during heading/flowering were identified to be of high importance (Hjelkrem et al. 2017). The discrepancy between the models developed to predict HT2 + T2 and DON in oats is supported by reports on the absence of significant correlations (Hofgaard et al. 2016a) or on negative associations (Edwards 2009) between HT2 + T2 versus DON in oats. The lack of a positive association between the mycotoxins HT2 + T2 and DON suggests that there is a competition between the fungal species that produce these mycotoxins, alternatively it may be that these fungi occupy different niches (Hofgaard et al. 2016a; Edwards 2009).

\section{Conclusions}

This study identified important associations between the HT2 + T2 content in oat grains and weather conditions during ten predicted growth stages defining host plant development. In the booting period, humid weather and cool in addition to moderate temperatures were associated with increased HT2 + T2 accumulation in harvested oat grains, whilst warm and humid weather during stem elongation and inflorescence emergence, in addition to cool and no rain during booting, reduced the risk of elevated HT2 + T2 levels. After flowering, warm and humid weather increased the risk of elevated HT2 + T2 levels, whilst moderate to warm temperatures and no rain during dough development reduced the risk of elevated $\mathrm{HT} 2+\mathrm{T} 2$ levels in oat grains. Our data showed that adequate predictions of the risk of elevated HT2 + T2levels in oat grains at harvest can be achieved, based upon weather data observed during the growing season. This study indicated that HT2 + T2 contamination in oats is influenced by weather conditions both pre- and postflowering, as opposed to models predicting the risk of DON contamination where weather conditions from flowering onwards were reported to be the most important. From our work it appears that the risk of elevated $\mathrm{HT} 2+\mathrm{T} 2$ and DON levels in oat grains is differentially influenced by the weather conditions during the preflowering and heading/flowering periods, whilst the 
weather conditions in the post-flowering period similarly influences both HT2 + T2 and DON accumulation. Despite being developed and validated only for Norwegian weather conditions, our prediction models may also be useful in other regions where spring oat is grown. The epidemiology of $F$. langsethiae and the HT2 + T2 accumulation is poorly understood. Our study provides valuable information in this context, but still more knowledge is needed both for developing agricultural control measures, and for the improvement of prediction models.

Acknowledgements We acknowledge all farmers who supplied grain samples. We also thank the workers at the different elevators and at the Norwegian Agricultural Extension Service, who coordinated with us to supply grain samples. Thanks to the staff at KIMEN Seed Laboratory for cleaning and milling the grain. This work was funded by: the Research Council of Norway (research grants 173277/I10 and 199412/I99), the strategic institute program PlantStrength at NIBIO, the Norwegian Levy on Agricultural Products/Agricultural Agreement Research Fund, Felleskjøpet Agri, Nordisk Korn/Fiskå Mølle, Norgesfôr/Strand Unikorn, Bayer Crop Science, Felleskjøpet Rogaland og Agder, Norgesmøllene, Braskereidfoss Kornsilo, Flisa Mølle og Kornsilo, Norkorn, Lantmännen Cerealia and Nibio. We also thank Inge Roer Hjelkrem for designing the icons for our figures.

\section{Compliance with ethical standards}

Conflict of interest There is no conflict of interest related to this research.

Open Access This article is distributed under the terms of the Creative Commons Attribution 4.0 International License (http:// creativecommons.org/licenses/by/4.0/), which permits unrestricted use, distribution, and reproduction in any medium, provided you give appropriate credit to the original author(s) and the source, provide a link to the Creative Commons license, and indicate if changes were made.

\section{References}

Aamot, H. U., Hofgaard, I. S., Brodal, G., Elen, O., Jestoi, M., \& Klemsdal, S. S. (2012). Evaluation of rapid test kits for quantification of deoxynivalenol in naturally contamined oats and wheat. World Mycotoxin Journal, 5(4), 339-350.

Aamot, H. U., Hofgaard, I. S., Brodal, G., Elen, O., Holen, B., \& Klemsdal, S. S. (2013). Evaluation of rapid kits for quantification of HAT-2 and T-2 toxins in naturally contaminated oats. World Mycotoxin Journal, 6(1), 31-41.

Agrometeorology Norway (2016). http://lmt.nibio.no. Accessed Dec 2017.

Andersen, K. F., Madden, L. V., \& Paul, P. A. (2015). Fusarium head blight development and deoxynivalenol accumulation in wheat as influenced by post-anthesis moisture patterns. Phytopathology, 105, 210-219.

Bernhoft, A., Torp, M., Clasen, P. E., Løea, A.-K., \& Kristoffersen, A. B. (2012). Influence of agronomic and climatic factors on fusarium infestation and mycotoxin contamination pf cereals in Norway. Food Additives and Contaminants, 29(7), 1129-1140.

Brodal, G., Hofgaard, I. S., Eriksen, G. S., Bernhoft, A., \& Sundheim, L. (2016). Mycotoxins in organically versus conventionally produced cereal grains and some other crops in temperate regions. World Mycotoxin Journal, 9, 755-770.

Coakley, S. M., Boyd, W. S., \& Line, R. F. (1982). Statistical models for predicting strip rust on winter wheat in the Pacific northwest. Phytopathology, 72(12), 1539-1542.

De Wolf, E.D., L.V. Madden, L.V., Lipps, P.E. 2003. Risk assessment models for wheat fusarium head blight epidemics based on within-season weather data. Phytopathology, 93, 428-435.

Edwards, S. G. (2009). Fusarium mycotoxin content in UK organic and conventional oats. Food Additives and Contaminants. Part A, Chemistry, Analysis, Control, Exposure and Risk Assessment, 26, 1063-1069.

Edwards, S.G. (2017). Impact of agronomic and climatic factors on the mycotoxin content of harvested oats in the United Kingdom. Food Additives and Contaminants: Part A. DOI: https://doi.org/10.1080/19440049.2017.1372639.

Edwards, S. G., Imathiu, S. M., Ray, R. V., Back, M., \& Hare, M. C. (2012). Molecular studies to identify the Fusarium species responsible for HT-2 and T-2 mycotoxins in UK oats. International Journal of Food Microbiology, 156, 168-175.

European Commission. (2003). Collection of occurrence of fusarium toxins in food and assessment of dietary intake by the population of EU member states. Bryssel: Belgium.

European Commission. (2013). Commission recommendation of 27 march 2013 on the presence of T-2 and HT-2 toxin in cereals and cereal products (2013/165/EU). Official Journal of European Union L, 91, 12-15.

Fredlund, E., Gidlund, A., Sulyok, M., Börjesson, T., Krska, R., Olsen, M., \& Lindblad, M. (2013). Deoxynivalenol and other selected Fusarium toxins in Swedish oats - Occurence and correlation to specific Fusarium species. International Journal of Food Microbiology, 167, 276-283.

Giroux, M. E., Bourgeois, G., Dion, Y., Rioux, S., Pageau, D., Zoghlami, S., Parent, C., Vachon, E., \& Vanasse, A. (2016). Evaluation of forecasting models for fusarium head blight of wheat under growing conditions of Quebec, Canada. Plant Disease, 100(6), 1192-1201.

Goff, J.A., Gratch, S. (1946). Low-pressure properties of water from -160 to 212 F. In Transactions of the American society of heating and ventilating engineers. New York: American Society of Heating and Ventilating Engineers.

Gourdain, E., Piraux, F., \& Barrier-Guillot, B. (2011). A model combining agronomic and weather factors to predict occuence of deoxynivalenol in durum wheat kernels. World Mycotoxin Journal, 4(2), 129-139.

Hjelkrem, A.-G. R., Torp, T., Brodal, G., Aamot, H. U., Strand, E., Nordskog, B., Dill-Macky, R., Edwards, S., \& Hofgaard, I. S. (2017). DON content in oat grains in Norway related to weather conditions at different growth stages. European Journal of Plant Pathology. https://doi.org/10.1007/s10658016-1113-5. 
Hofgaard, I. S., Aamot, H. U., Torp, T., Jestoi, M., Lattanzio, V. M. T., Klemsdal, S. S., Waalwijk, C., Van der Lee, T., \& Brodal, G. (2016a). Associations between Fusarium species and mycotoxins in oats and spring wheat from farmers' fields in Norway over a six-year period. World Mycotoxin Journal, 9(3), 365-378.

Hofgaard, I. S., Seehusen, T., Aamot, H. U., Riley, H., Razzaghian, J., Le, V. H., Hjelkrem, A. G. R., Dill-Macky, R., \& Brodal, G. (2016b). Inoculum potential of Fusarium spp. relates to tillage and straw management in Norwegian fields of spring oats. Frontiers in Microbiology, 7, 556.

Imathiu, S. M., Edwards, S. G., Ray, S. R. V., \& Back, M. A. (2013). Fusarium langsethiae - A HT-2 and T-2 toxins producer that needs more attention. Journal of Phytopathology, 161, 1-10.

Imathiu, S. M., Ray, R. V., Back, M., Hare, _. M., \& Edwards, S. G. (2016). In vitro growth characteristics of Fusarium langsethiae isolates recovered froam oats and wheat grain in the UK. Acta Phytopathological et Entomologica Hungarica, 51(2), 159-170.

Kokkonen, M., Medina, A., \& Magan, N. (2012). Comparative study of water and temperature relations of growth and T-2/ HAT-2 toxin production by strains of Fusarium sporotrichioides and Fusarium langsethiae. World Mycotoxin Journal, 5(4), 365-372.

Kriss, A. B., Paul, P. A., \& Madden, L. V. (2010). Relationship between yearly Fluctations in fusarium Gead blight intensity and environmental variables: A window-pane analysis. Phytopathology, 100(8), 784-797.

Lancashire, P. D., Bleiholder, H., Van Den Boom, T., Langelüddeke, P., Stauss, R., Weber, E., \& Witzenberger, A. (1991). A uniform decimal code for growth stages of crops and weeds. Annals of Applied Biology, 119(3), 561-601.

Langseth, W., \& Rundberget, T. (1999). The occurrence of HAT-2 toxin and other trichothecenes in Norwegian cereals. Mycopathologia, 147, 157-165.

Medina, A., \& Magan, N. (2011). Temperature and water activity effects on production of T-2 and HT-2 by Fusarium langsetiae strains from north European countries. Food Microbiology, 28, 392-398.

Montgomery, D.C., Peck, E.A., Vining, C.G. (2001). Introduction to linear regression analysis. New York: Wiley Interscience, Third edition.

Nathanail, A. V., Syvähoko, J., Malachová, A., Jestoi, M., Varga, E., Michlmayr, H., Adam, G., Sieviläinen, E., Berthiller, F., \& Peltonen, K. (2015). Simultaneous determination of major type a and B trichothecenes, zeralenone and certain modified metabolotes in Finnish cereal grains with novel liquid chromatogrphy-tandem mass spectrometric method. Analytical and Bioanalytical Chemistry, 407(16), 4745-4755.

Nazari, L., Pattori, E., Terzi, V., Morcia, C., \& Rossi, V. (2014). Influence of temperature on infection, growth , and mycotoxin production by Fusarium langsethiae and F. sporotrichioides in durum wheat. Food Microbiology, 39, 19-26.

Norwegian Scientific Commitee for Food Safety (2013). Risk assessment of mycotoxins in cereal grain in Norway. Opinion of the Scienific steering Committe of the Norwegian scientific Commitee for food safety. Oslo, Norway.

Opoku, N., Back, M., \& Edwards, S. G. (2013). Development of Fusarium langsethiae in commercial cereal production. European Journal of Plant Pathology, 136(1), 159-168.

Parikka, P., Hietaniemi, V., Rämö, S., \& Jalli, H. (2007). The effect of cultivation practices on Fusarium langsethiae infection of oats and barley. Fusarium disease in cereals -potential impact from sustainable cropping systems. Proceedings of the COST SUSVAR Fusarium workshop, Vogelsang. Velence, Hungary (01-02 June 2007).

Perry, R. H., \& Green, D. W. (1997). Perry's chemical Engineers' handbook. New York: McGraw-Hill.

Schirdewahn, T., Martin, C., Mascher, F., Bucheli, T.D., Bertossa, T.D., Musa, T., Vobelsang, S. (2016). Elicidating the cropping factors influencing Fusarium species and mycotoxin occurrence in Swiss oats. Oats 2016: St Petersburg. http://oats2016.org/files/present/2/4/5.pdf.

Shakery, B. (2012). Effect of chemical- and biological treatments on Fusarium infection and mycotoxins in oats. Master thesis, University of Life Sciences, Ås, Norway.

Spearman, C. (2010). The proof and measurement of association between two things. International Journal of Epidemiology, 39(5), 1137-1150.

Tekle, S., Dill-Macky, R., Skinnes, H., Tronsmo, A., \& Bjørnstad, Å. (2012). Infection process of Fusarium graminearum in oats (Avena Sativa L.) European Journal of Plant Pathology, 132(3), 431-442.

Torp, M., \& Langseth, W. (1999). Production of T-2 toxin by a Fusarium resembling Fusarium Poae. Mycopathologia, 147(2), 89-96.

Torp, M., \& Nirenberg, H. I. (2004). Fusarium langsethiae sp. Nov. on cereals in Europe. International Journal of Food Microbiology, 95, 247-256.

World Meteorological Organisation. (2012). General Meteorological Standards and Recommended Practices. Gineva: WMO, 49.

Xu, X., Madden, L. V., Edwards, S. G., Doohan, F. M., Moretti, A., Hornok, L., \& Nicholson, P. (2013). Developing logistic models to relate the accumulation of DON associated with fusarium head blight to climatic conditions in Europe. European Journal of Plant Pathology, 137(4), 689-706.

$\mathrm{Xu}$, X., Madden, L. V., \& Edwards, S. G. (2014). Modelling the effects of environmental conditions on HT2 and T2 toxin accumulation in field oat grains. Phytopathology, 104(1), 57-66. 